Original Article

\title{
CROSS SECTIONAL STUDY OF ATTITUDE, PRACTICE AND KNOWLEDGE OF ORAL HYGIENE PRACTICES AND DENTAL TREATMENT IN HEALTH CARE PROFESSIONALS IN SOUTH CANARA DISTRICT.( KARNATAKA)
}

\author{
Sharath K.S. ${ }^{1}$, Manavi Prabhu ${ }^{2}$, Biju Thomas ${ }^{3} \&$ Shamila Shetty ${ }^{4}$ \\ ${ }^{1}$ Professor, ${ }^{2}$ Post Graduate, ${ }^{3} \mathrm{HOD} \&$ Professor, ${ }^{4}$ Assistant Professor, Departments of Periodontics, A.B. Shetty M emorial \\ Institute of Dental Sciences, Nitte University, Mangalore - 575 018, India. \\ Correspondence: \\ Manavi Prabhu \\ Departments of Periodontics, A.B.Shetty M emorial Institute of Dental Sciences, Nitte University, Mangalore-575018, India \\ E-mail ID : manavi.shammi@yahoo.co.in M obile : +91 944895396
}

\begin{abstract}
:
Objective: The purpose of the studyis to estimate the knowledge, attitude and practise of the oral hygiene, and dental treatment, and its correlation with everyday oral hygiene practices among the health care professionals of south canara district ( Karnataka)

Methods : A cross sectional survey was conducted on 200 health care professionals between Jan $20^{\text {th }}$ to Feb $20^{\text {th }} 2013$.Two hundred health professionals were asked to answer a questionnaire containing 15 questions.Data once collected was analysed using SPSS software.

Results: $56.3 \%$ health professionals visited the dentist once in six months. $26 \%$ health professionals felt that unavailability of time is the main factor influencing dental visits. M ain cause of taking a dental appointment in 33\% subjects was found to be dental caries. $54.6 \%$ obtained information on oral hygiene practices through mass media followed by $22.3 \%$ who obtained it directly from the dentist. $59.2 \%$ brushed their teeth twice daily. $50 \%$ used medium bristle to oth brush. $48.5 \%$ had a brushing time of 3-5 min. $41.5 \%$ did not use any other oral hygiene aid $.28 .64 \%$ got scaling done in the last $3-6$ months. $56 \%$ did not have an habit of using a tooth pick. $43.3 \%$ used combination of circular, vertical and horizontal method of brushing. $45.5 \%$ felt that scaling caused loss of enamel.

Conclusion: It appears that knowledge, attitude, and behaviour attitude, practice and knowledge of oral hygiene practices and dental treatment in health care professionals in South Canara district is gud.Though more information needs to be provided about other oral hygiene aids.
\end{abstract}

Keywords : oral hygiene, tooth brushing, flossing, oral hygiene practices

\section{Introduction:}

It is a well known fact that bacterial plaque plays a critical role in the host response leading to the pathogenesis of periodontitis.Poor oral hygiene and exogenous infection change the normal flora into a pathogenic flora. It is a well understood fact that bacterial plaque is involved in pathogenesis of Access this article online Quick Response Code

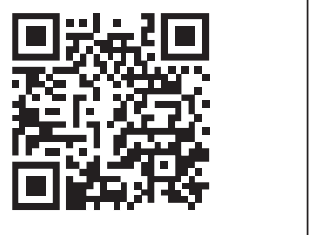

hygiene in maintenance of gingival health.

It has been demonstrated that an effective supragingival oral hygiene even may affect the sub

gingival microbiota ${ }^{2}$.Effective plaque control is the cornerstone of any attempt to prevent and control periodontal diseases. It was demonstrated that plaque also plays an important role in dental caries ${ }^{3}$, gingivitis ${ }^{4}$ and periodontal diseases ${ }^{5}$

The use of other oral hygiene aids may improve tooth cleaning effectiveness provided that cleaning is sufficiently thorough and performed at appropriate intervals. Tooth brushing $^{6}$ and flossing ${ }^{7}$ are reported to be fundamental 
to reduce the amount of bacterial plaque and its virulence potential, so they are considered the pillar of selfprevention strategy ${ }^{8}$.Several studies have shown the usefulness of regular dental flossing for removing interdental plaque and preventing calculus formation ${ }^{9}$. Both the American Dental Association and the British Dental Association recommended the daily use of dental floss in addition to brushing.

Axelsson and lindhe ${ }^{10}$ and Hellstrom et al. (Hellstrom, Ramberg, Krok \& Lindhe 1996) found in a longitudinal study that it was possible to minimize periodontal attachment loss and bone resorption with a combination of improved oral hygiene and professional prophylaxis 6 to 8 times a year. Irregular or not frequent users of dental services have less restored teeth and higher number of carious teeth. ${ }^{11}$

Hence good oral hygiene practices and routine dental visits show a positive result for the preservation of a natural and functional dentition.

The aim of the current study was to investigate knowledge, attitude and practices of oral hygiene and the attitude towards preventive dental visits among health care professionals in south canara district, Karnataka.

\section{Materials and methods:}

A cross sectional survey was conducted on 200 health care professionals between Jan $20^{\text {th }}$ to Feb $20^{\text {th }}$, 2013. Ethical clearance was obtained and consent was taken from all the subjects. The health care professionals included professionals from the field of Physiotherapy, Nursing, Psychiatry and Medicine.200 health care professionals were asked to answer a questionnaire containing 15 questions.The questions were in relation to the knowledge , attitude and practice of oral hygiene and attitude towards preventive dental visits among health care professionals. The health care professionals were in the age group of 23 to 40 yrs.Which included working graduates and post graduate students.Once the forms were collected, Data was entered in an MS Excel spreadsheet and analyzed thrsough SPSS16.0

\section{Results:}

The results are presented in Tab. 1-14

\section{Source of information on oral hygiene practices}

Table 1: From where do you obtain your information on oral hygiene practices?

\begin{tabular}{|l|c|}
\hline Source & Percentage \\
\hline from the doctor/ dentist & 22.3 \\
\hline from mass media & 54.6 \\
\hline from family and acquantances & 4 \\
\hline from school/college & 19.1 \\
\hline
\end{tabular}

Table 1 gathers the answers concerning the sources of information about the rules of oral hygiene. $54.6 \%$ obtained the information from mass media. $22.3 \%$ obtainted it directly from the dentist. Family and acquaintances were the source for the remaining $4 \%$.

\section{Flossing}

Table 2 : Do you have any information regarding flossing?

\begin{tabular}{|l|c|}
\hline Number & percentage \\
\hline No & 19.5 \\
\hline Yes & 80.5 \\
\hline
\end{tabular}

Among all the subjects $61 \%$ had information regarding flossing and $39 \%$ were ignorant about flossing.

\section{Scaling effect on enamel}

Table 3 : Do you feel scaling causes loss of enamel?

\begin{tabular}{|l|c|}
\hline Option & Number of subjects \\
\hline Yes & 91 \\
\hline No & 103 \\
\hline Don't know & 6 \\
\hline
\end{tabular}

Table 3: showed whether the health care professional felt that scaling caused loss of enamel. It can be seen that $45.5 \%$ subjects felt that scaling caused loss of to oth material.

\section{Dental visits}

Table 4 : Factors influencing dental visits

\begin{tabular}{|l|c|}
\hline Factor & Percentage \\
\hline Fear & 26 \\
\hline Lack of financial means & 10 \\
\hline Lack of availability of time & 52 \\
\hline Lack of availability of dentist & 32 \\
\hline
\end{tabular}

Table 4: presents the factors influencing dental visits. M ost often mentioned cause was unavailability of time in $52 \%$ subjects. Another cause was lack of availability of dentist as mentioned by $32 \%$ students of dentistry. Fear of dental visit was mentioned by $26 \%$ subjects. Additionally $10 \%$ felt the lack of financial means was among the main causes which affected the frequency of making a dental appointment.

\section{Chief complaint}

Table 5: What is the main cause of making a dental appointment?

\begin{tabular}{|l|c|}
\hline Cause & Percentage \\
\hline Depositsand stainson the teeth & 21.89 \\
\hline Dental caries & 33.33 \\
\hline Dental pain & 27.36 \\
\hline Orthodontic treatment and other causes & 17.41 \\
\hline
\end{tabular}


Table 5 lists most common causes that motivate to make a dental appointment. Dental caries was mentioned by $33.33 \%$ as the main cause of making a dental appointment. 27.36 felt that dental pain was the main cause followed by 21.89 subjects who felt deposits and stains on the teeth was the main cause.

Table 6: when was the last time you got a professional scaling done?

\begin{tabular}{|l|c|}
\hline frequency & Percentage \\
\hline Never & 26.63 \\
\hline Last 3- 6 months & 28.64 \\
\hline Last year & 24.62 \\
\hline M ore than an year back & 19.1 \\
\hline
\end{tabular}

Table 6 : showed when last the health professionals got their teeth professionally cleaned. It can be seen that $28.64 \%$ got it cleaned in the last 3-6 months.26.63\% never got their teeth cleaned.24.62 got their teeth cleaned last year. The remaining $19.1 \%$ got it done one year back

Table 7: How often do you visit a dentist?

\begin{tabular}{|l|c|}
\hline Frequency & percentage \\
\hline Every3 months & 8.7 \\
\hline Every6 months & 56.3 \\
\hline once a year & 8.2 \\
\hline less than once a year & 14 \\
\hline no definite frequency & 26.8 \\
\hline
\end{tabular}

Tab. 7 presents the results concerning the frequency of dental visits. It revealed that $56.3 \%$ subjects made a dental visit every 6 months. $26.8 \%$ subjects did not have any definite frequency. $14 \%$ visited the dentist less than once in an year.8.2\% visited the dentist once in an year and $8.7 \%$ of them visited once in 3 months.

\section{Brushing frequency}

Table 8: What is your brushing frequency?

\begin{tabular}{|l|c|}
\hline Frequency & Percentage \\
\hline After every meal & 22.3 \\
\hline Twice daily & 54.6 \\
\hline Once daily & 4 \\
\hline Lessthan once daily & 19.1 \\
\hline
\end{tabular}

The remaining few questions were regarding oral hygiene practices of the subjects. It was noticed that $54.6 \%$ subjects had a brushing frequency of twice dialy. $4 \%$ brushed once daily. Brushing after every meal was done by $22.3 \%$ subjects.

\section{Tooth brush bristle}

Table 9: Which type of tooth brush bristle you use?

\begin{tabular}{|l|c|}
\hline Type & Number of subjects \\
\hline Soft & 101 \\
\hline medium & 74 \\
\hline Hard & 7 \\
\hline Don't know & 18 \\
\hline
\end{tabular}

Table 9 showed the type of bristle used by the subjects. $50.5 \%$ of the subjects used soft bristle. $37 \%$ used medium bristle.3.5\% used hard bristle and $9 \%$ were not sure about the type of bristle they used.

\section{Brushingtime}

Table 10: How long do you brush?

\begin{tabular}{|l|c|}
\hline Brushing time & Percentage \\
\hline 1-3 $\mathrm{min}$ & 33.35 \\
\hline 3-5 $\mathrm{min}$ & 48.5 \\
\hline More than 5 min & 9.5 \\
\hline Less than 1 min & 5.0 \\
\hline
\end{tabular}

Table 10: brushing time varied in different subjects with $48.5 \%$ brushing for 3-5 min, followed by $33.35 \%$ who brushed for $1-3$ min. brushing for more than 5 min was seen in $9.5 \%$ subjects. Less than 1 min brushing time was seen in $5 \%$ of the population.

\section{Other oral hygiene aid}

Table 11: Do you use any other oral hygiene aid?

\begin{tabular}{|l|c|}
\hline Type of other oral hygiene aid used & Percentage \\
\hline Floss & 15.5 \\
\hline M outhwash & 29.5 \\
\hline Interdental brush & 14.5 \\
\hline none & 41.5 \\
\hline
\end{tabular}

Table 11 discussed the usage of other oral hygiene aids in health care professionals $41.5 \%$ subjects did not use any other oral hygiene aid.29.5\% used mouthwash. Only 15.5 subjects used floss. And $14.5 \%$ used interdental brush.

Table 12: If you have information regarding flossing, what is the frequency of your flossing?

\begin{tabular}{|l|c|}
\hline Frequency & Number of subjects \\
\hline Never & 133 \\
\hline Once a week & 44 \\
\hline Once a day & 13 \\
\hline M ore than once a day & 10 \\
\hline
\end{tabular}

Table 12: table ten represented the frequency of brushing among the subjects.133 subjects did not have the habit of flossing. 44 subjects flossed once in a week.13 flossed once in a day.flossing more than once in a day was seen among 10 subjects.

\section{Tooth pick uses age}

Table 13: Do you have the habit of using tooth pick?

\begin{tabular}{|l|c|}
\hline Habit & Percentage \\
\hline after every meal & $12 \%$ \\
\hline whenever required & $38 \%$ \\
\hline no habit of using tooth pick & $56 \%$ \\
\hline
\end{tabular}

Table 13: table 12 discussed the prevalence of using tooth pick. $56 \%$ had no habit of using tooth pick.38\% used tooth pick only when required. $12 \%$ used it after every meal

\section{Brushingmethod}

Table 14: What is the brushing method you use?

\begin{tabular}{|l|c|}
\hline Method & frequency \\
\hline Circular & 19.4 \\
\hline Vertical & 19.9 \\
\hline Horizontal & 10.9 \\
\hline Combination of all of the above & 43.3 \\
\hline No particular method & 5.6 \\
\hline
\end{tabular}

Table 14 represented the brushing techniques used by the subjects, it was seen that $43.3 \%$ subjects used a combination of vertical, horizontal and circular brushing method.19.4\% had a circular method of brushing. Vertical horizontal and 
circular brushing method. $19.4 \%$ had a circular method of brushing. Vertical brushing technique was used by $19.9 \%$ subjects. Horizontal brushing method was used by $10.9 \%$.

\section{Discussion :}

The present study investigated the knowledge, attitude and practice towards oral hygiene practices and the attitude towards preventive dental visits of a group of health care professionals.

In the cross sectional study questions were asked to check the knowledge about oral hygiene practices. When asked from where the subjects obtained information on oral hygiene practices, it was observed that $54.6 \%$ obtained the information from mass media. $22.3 \%$ obtainted it directly from the dentist. Family and acquaintances was the source for the remaining $4 \%$.

The subjects were asked whether they had any information regarding flossing. It was noticed in our study that among all the subjects $61 \%$ had information regarding flossing and $39 \%$ were ignorant about flossing.

There is a common misnomer that scaling causes loss of enamel. Enamel is $97 \%$ mineralised. Scaling once in six months will not cause any harmful effect on enamel. The general population should be educated about this fact that undergoing a professional scaling once in six months is very beneficial and should be encouraged.

The subjects answered questions related to their attitude towards oral hygiene practices and dental visits. The subjects were asked about the main factors which influenced the frequency of dental visits. Most often mentioned cause was unavailability of time in 52\% subjects. Another cause was lack of availability of dentist as mentioned by $32 \%$. Fear of dental visit was mentioned by $26 \%$ subjects. Additionally $10 \%$ felt the lack of financial means was among the main causes which affected the frequency of making a dental appointment.

The subjects were asked what is the main cause of visiting a dentist. Dental caries was mentioned by $33.33 \%$ as the main cause of taking a dental appointment. Following which $27.36 \%$ felt its dental pain. 21.89 subjects who felt deposits and stains on the teeth was the main cause. This showed that subjects were more concerned about dental problems which were related to pain and which effected aesthetics. Hence subjects should be educated about other dental problems which are usually ignored, for instance bleeding gums, recession, mobility etc and thus they should be motivated to treat these problems too at the right time.

The subjects were asked when last the health professionals got their teeth professionally cleaned. The effects of periodontal maintenance care provided every 6 months were compared over 4 years according to Lightner et al. ${ }^{16}$ Results indicated that plaque and gingivitis scores improved more in groups receiving more frequent maintenance. Similar results was found by Listgarten et al. ${ }^{17}$ and by Rosen et al. ${ }^{18}$, they suggested that recall intervals can be extended upto a year for the purpose of reducing periodontal disease progression in individuals with a history of limited susceptibility to the disease. It could be seen in our study that $28.64 \%$ got it cleaned in the last 3-6 months. $26.63 \%$ never got their teeth cleaned.24.62\% got their teeth cleaned last year. The remaining $19.1 \%$ got it done one year back.

It's well known that, professional plaque removal and regular follow up combined with patient oral hygiene instructions could minimize the level of gingival inflammation and swelling ${ }^{12}$. Lang et al. ${ }^{13}$ demonstrated that students who thoroughly removed plaque at least every second day, did not develop clinical signs of gingival inflammation over a 6 -week period. This included the use of inter-proximal aids as well as the toothbrush. A recommendation to brush the teeth twice daily should be considered ${ }^{14}$, particularly in patients showing gingival inflammation. The results in the present study indicate that $54.6 \%$ subjects had a brushing frequency of twice dialy, $4 \%$ brushed once daily. $22.4 \%$ had the practice of brushing after every meal.

Opinions regarding the merits of hard and soft bristles are based on studies that are not comparable, are often inconclusive, and contradict one another. ${ }^{19}$ Softer bristles 
are more flexible, clean slightly below the gingival margin when used with a sulcular brushing technique and farther into proximal surfaces.$^{20}$ Use of hard bristled tooth brushes is associated with more gingival recession, and frequent brushers who use hard bristles have more recession than those who use soft bristles. ${ }^{21}$ In our study, we could see that $50 \%$ health care professionals preferred to use medium bristle tooth brush. Results showed that, $48.5 \%$ subjects had a brushing time of 3-5 min followed by $33.5 \%$, who had a brushing time of 1-3 min.

Many studies proved that by interdental cleaning, periodontal patients are able to improve clinical outcomes and reduce clinical signs of disease and inflammation ${ }^{15}$.In our study $41.5 \%$ subjects did not use any other oral hygiene aid like mouth wash, floss and tooth pick. It was seen that $29.5 \%$ used mouthwash. $15.5 \%$ subjects used floss and $14.5 \%$ used interdental brush. Hence there is a clear need for motivation among the subjects to use other oral hygiene aids.

\section{Conclusion:}

From the above survey it can be seen that majority of the health care professionals are quite aware about the various

\section{References:}

Vega KJ, Pina I, Krevsky B. Heart transplantation is associated with an increased risk for pancreatobiliary disease. Ann Intern Med 1996; 124: 980-3.

1. Offenbacher S. Periodontal diseases: Pathogenesis.Ann Periodontol 1996; 1: 821-878.

2. Dahlen G, Lindhe, J, Sato K, Hanamura H. \& Okamoto H. The effect of supragingival plaque control on the subgingival microbiota in subjects with periodontal disease. JClin Periodontol 1992; 19: 802-809.

3. Ainamo J. Relative roles of toothbrushing, sucrose consumption and fluorides in the maintenance of oral health in children. Int Dent J 1980; 30: 54-66.

4. Ainamo J, Holmberg S. A retrospective longitudinal study of caries prevalence during and 7 years after free dental care at school in finland. Community Dent Oral Epidemiol 1973 1: 30-36.

5. Lang NP, Cumming BR, Loe, Toothbrushing frequency as it relates to plaque development and gingival health.J Periodontol 1973; 44: 396-405.

6. Hansen $F$, Gjermo P. The plaque-removing effect of four toothbrushing methods. Scand J Dent Res 1971; 79: 502-506.

7. Hill H.C, Levi, Glickman I. The effects of waxed and unwaxed dental floss on interdental plaque accumulation and interdental gingival health. 1973; J Periodontol 44: 411-413.

8. Schmid M O, Balmelli OP, Saxer UP. Plaque removing effect of a tooth brush, dental floss, and a toothpick. J Clin Periodontol1976; 3: 157-165.

9. Bauroth, $\mathrm{K}$, Charles $\mathrm{CH}$, Mankodi SM. The efficacy of an essential oil antiseptic mouthrinse vs. Dental floss in controlling interproximal gingivitis: A comparative study.2003; J Am Dent Assoc 134: 359-365.

10. Axelsson $P$, Lindhe J. Effect of controlled oral hygiene procedures on caries and periodontal disease in adults. Results after 6 years. J Clin Periodontol .1981; 8: 239-248 health care practices. Though more emphasis should be put on usage of other oral hygiene aids. They should be educated about the advantages of using other oral hygiene aids and should be encouraged to use the same.

It can be clearly seen that most of the subjects had main chief complaint of caries and dental pain. These symptoms are important and subjects tend to notice them as they are associated with pain and aesthetics. Deposits and stains on teeth, bleeding gums, recession, and mobility are mostly ignored, so the subjects should be educated about these symptoms. They should be told the consequence of not getting the right treatment at the right time.

The misconception among subjects about loss of enamel during scaling should be corrected. Enamel is the most mineralized tissue in the body with $97 \%$ mineral content, so undergoing scaling once in 6 months would not be detrimental to the enamel. Subjects should be encouraged to undergo a scaling once in six months.

Hence, Professional plaque removal and regular follow up combined with patient oral hygiene instructions can minimize the level of dental and periodontal diseases.

11. Davenport C, Elley K, Salas C, Taylor-Weetman. The clinical effectiveness and cost-effectiveness of routine dental checks: A systematic review and economic evaluation. Health Technol Assess 2003; 7: iii-v, 1-127.

12. Raber-Durlacher JE, van Steenbergen TJ, Van der Velden U. Experimental gingivitis during pregnancy and post-partum: Clinical, endocrinological, and microbiological aspects. J ClinPeriodontol 1994;21: 549-558.

13. Lang NP, Cumming BR, Loe $\mathrm{H}$. Toothbrushing frequency as it relates to plaque development and gingival health. J Periodontol1973; 44: 396-405.

14. Echeverria JJ, M anlau,Tejerina JM fundamentals of periodontal treatment. Arch Odonto Estomatol1987 3: 359-364.

15. Christou V, Timmerman MF, Van der Velden U.Comparison of different approaches of interdental oral hygiene: Interdental brushes versus dental floss. J Periodontol 1998;69: 759-764.

16. Lightner L M, O'Lear JT, Drake RB. Preventive periodontic treatment procedures: Results over 46 months.J Periodontol 1971;42: 555-561.

17. Listgarten MA, Sullivan P, George C. Comparative longitudinal study of 2 methods of scheduling maintenance visits:4-year data. J Clin Periodontol1989; 16: 105-115.

18. Rosen B, Olavi G, Badersten. Effect of different frequencies of preventive maintenance treatment on periodontal conditions.5-year observations in general dentistry patients. J ClinPeriodontol1999; 26: 225-233.

19. Hinijker jj, Forscher BK.The effect of tooth brush type on gingival health,j periodontal 1954:25:40.

20. Bass CC.An effective method of personal oral ygiene.part II, j la state med soc 106:100.1948se, j periodont

21. khocht A,Simon G, Person P. gingival recession in relation tp history of hard tooth brush use,j periodontal 1993;64:900. 